\title{
Rancang Bangun Media Pembelajaran Pengenalan Kombinasi Warna Berbasis Mikrokontroler dengan Visualisasi Desktop
}

\author{
Muhammad Yasir Bintang Nugraha ${ }^{1}$, Rudi Susanto ${ }^{2}$, Afu Ichsan Pradana ${ }^{3}$ \\ Fakultas Ilmu Komputer, Universitas Duta Bangsa Surakarta; J1. Bhayangkara no 55 Tipes, Surakarta \\ Email: rudi_susanto@udb.ac.id
}

\begin{abstract}
The purpose of this study was to create a learning media for color combination recognition that serves to help introduce colors and color combinations to the students of Al-Amin 3 Cemani Kindergarten. The stages of developing this color combination application consist of analysis, design, manufacture and testing. This learning media work system uses the Arduino Uno R3 (ATMEGA328) as a data processing center, TCS230 sensors as data input media. The data from Arduino Uno R3 processing results is displayed via RGB LED and a Visual Basic 2012-based desktop application. In the desktop application, the data input for color 1 and color 2 is processed through the combination button found in the application to combine color 1 and color 2. Overall test results, media learning color recognition and color combinations can work well in combining colors according to Munsell's Color Theory.
\end{abstract}

Keywords: Combinations, Learning Media, Arduino Uno, Visual Basic

\begin{abstract}
Abstrak: Tujuan penelitian ini adalah untuk membuat suatu media pembelajaran pengenalan kombinasi warna yang berfungsi untuk membantu mengenalkan tentang warna dan kombinasi warna pada siswa TK Al-Amin 3 Cemani. Tahapan pengembangan aplikasi kombinasi warna ini terdiri dari analisis, perancangan, pembuatan dan pengujian Sistem kerja media pembelajaran ini menggunakan Arduino Uno R3 (ATMEGA328) sebagai pusat pengolahan data, sensor TCS230 sebagai media input datanya. Data hasil pemrosesan Arduino Uno R3 ditampilkan melalui RGB LED dan aplikasi desktop berbasis Visual Basic 2012. Pada aplikasi desktop data input warna 1 dan warna 2 diolah melalui tombol kombinasi yang terdapat pada aplikasi untuk mengkombinasikan warna 1 dan warna 2 . Hasil pengujian secara keseluruhan, media pembelajaran pengenalan warna dan kombinasi warna sudah dapat bekerja dengan baik dalam mengkombinasikan warna sesuai dengan Teori Warna Munsell
\end{abstract}

Kata kunci: Kombinasi Warna, Media pembelajaran, Arduino Uno, Visual Basic

\section{PENDAHULUAN}

Pendidikan bagi anak usia dini adalah pemberian upaya untuk menstimulasi, membimbing, mengasuh dan pemberian kegiatan pembelajaran yang akan menghasilkan kemampuan dan ketrampilan anak (Grindal, 2016). Anak TK usia 4-5 tahun merupakan usia anak pra sekolah dan termasuk dalam pendidikan usia dini yang harus mendapatkan rangsangan pendidikan untuk pertumbuhan dan perkembangan dalam memasuki pendidikan pada tingkat lebih lanjut. Sehingga pendidikan usia dini memiliki peran dalam meningkatkan produktifitas kerja pada masa dewasa.

Pada usia ini merupakan masa perkembangan aspek-aspek kemampuan dasar seperti kognitif, bahasa, dan motorik maupun aspek perkembangan kemampuan lainnya yang akan membentuk karakter anak kelak. Dari beberapa aspek kemampuan dasar tersebut, perkembangan kognitif adalah salah satu aspek penting yang harus dikembangkan untuk kemampuan berpikir anak (Holis, 2016). Hal ini agar anak dapat mengelola perolehan belajarnya, memecahkan masalah, membantu anak untuk mengembangkan kemampuan logika 
matematika dan pengetahuan akan ruang dan waktu, serta mempersiapkan pengembangan kemampuan berpikir teliti.

Salah satu aspek dari kemampuan kognitif yaitu kemampuan mengenal warna. Kemampuan mengenal warna pada anak usia dini merupakan hal yang sangat penting bagi perkembangan otaknya, sebab pengenalan warna mampu merangsang indera penglihatan pada otak. Pembelajaran pada jenjang TK dalam merangsang aspek kognitif anak adalah dengan melalui pengenalan warna dan kombinasinya (Suciati, 2016) (Muliani, 2017) (Nofitasari, 2018).

Pada penelitian ini penulis melakukan pengamatan pembelajaran pengenalan warna dan kombinasi warna di TK Al-Amin 3 Cemani. Proses pembelajaran pengenalan warna dan kombinasi warna di TK Al-Amin 3 Cemani menggunakan pasta cat sebagai media pembelajaran, namun masih memiliki beberapa kendala pada penggunaan pasta cat tersebut antara lain : 1) Anak merasa enggan saat memegang pasta warna sehingga anak tidak mempraktikan dan pengajar yang harus mempraktikan saat pembelajaran berlangsung. 2) Persiapan pengajar dan pengkondisian anak yang memakan waktu lama saat akan melakukan praktikum kombinasi warna. 3) Antisipasi permasalahan yang rumit.

Berkaitan dengan permasalahan di atas, maka peneliti membangun sebuah media pembelajaran pengenalan kombinasi warna yang lebih efektif dan efisien dengan memanfaatkan Mikrokontroller. Media pembelajaran dikemas dalam bentuk hardware dan software. Hardware digunakan sebagai inputan warna yang akan dikombinasikan yang diintegrasikan dengan software sebagai luaran dari hasil kombinasi warna yang diinputkan. Software dikemas dengan tampilan yang menarik dan dilengkapi dengan audio sehingga siswa mudah memahami materi yang disampaikan pada proses pembelajaran.

\section{METODE PENELITIAN}

Tahapan pengembangan aplikasi disajikan sesuai gambar 1 yaitu analisis, perancangan, pembuatan dan pengujian. a) Analisis, pada tahap ini dilakukan analisa terkait informasi yang telah dikumpulkan sebagai pedoman pengembangan alat. Sumber informasi diperoleh melalui observasi, wawancara, jurnal, karya tulis ilmiah dan media online. b)Perancangan, tahap perancangan hardware sesuai dengan desain alat meliputi pembuatan diagram blok alat, desain rangkaian elektronik dan desain bentuk alat. Serta perancangan software sesuai dengan desain software meliputi pembuatan alur proses mengunakan flowchart. c)Pembuatan, tahap pembuatan alat baik dari segi hardware maupun software yang berdasarkan pada desain yang telah dibuat pada tahap perancangan. d) Pengujian, pada tahap ini dilakukan pengujian alat terhadap pengajar dalam proses pembelajaran pengenalan kombinasi warna di TK Al-Amin 3 Cemani.

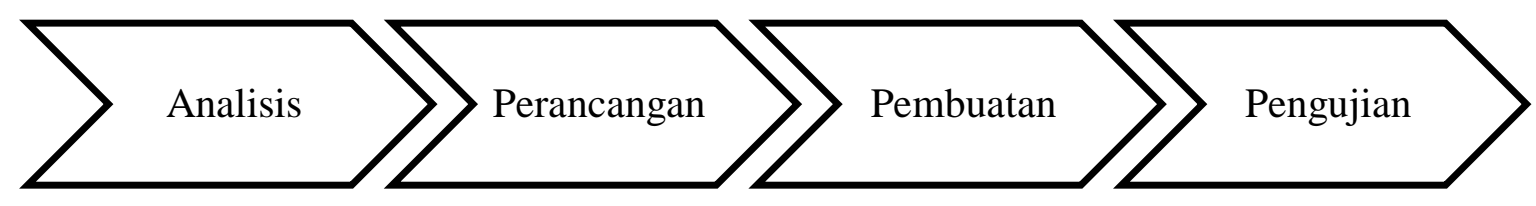

Gambar 1. Tahapan pengembangan media pembelajaran kombinasi warna 


\section{HASIL DAN PEMBAHASAN}

\subsection{Analisis}

Langkah pertama yang dilakukan adalah analisis kebutuhan, studi literatur dan observasi. Adapun hasil yang didapat melalui wawancara dengan guru adalah sebagai berikut: a) Media pembelajaran pada proses pembelajaran yang digunakan berupa cat pasta yang dalam persiapan dan penyesuaian terhadap siswa membutuhkan waktu yang lama. b) Pembelajaran yang berpusat pada guru bukan pada siswa, karena masih terdapat beberapa siswa yang enggan saat memegang pasta cat sehingga membuat siswa kurang aktif.

Berdasarkan hasil analisis tersebut disimpulkan bahwa perlu dibangun suatu media pembelajaran yang lebih efektif dan efisien untuk membantu pengajar dalam proses pembelajaran pengenalan warna dan kombinasi warna, maka penulis merancang sebuah media pembelajaran yaitu sebuah media pembelajaran berbasis mikrokontroller yang dikemas dalam bentuk hardware dan software. Hardware digunakan sebagai inputan warna yang akan dikombinasikan yang diintegrasikan dengan software sebagai hasil luaran dari kombinasi warna yang diinputkan. Software dikemas dengan tampilan yang menarik dan dilengkapi dengan audio sehingga siswa mudah memahami materi yang disampaikan pada proses pembelajaran.

\subsection{Perancangan}

Rencana teknis pertama pada tahap perencanaan ini adalah membuat diagram blok. Fungsi dari diagram blok adalah sebagai acuan dalam pembutan alur sistem kerja hardware. Penentuan diagram blok yang tepat akan menentukan hasil ide yang diinginkan dalam membuat media pembelajaran yang akan dibangun. Gambar 2 merupakan diagram blok alat yang akan dibangun.

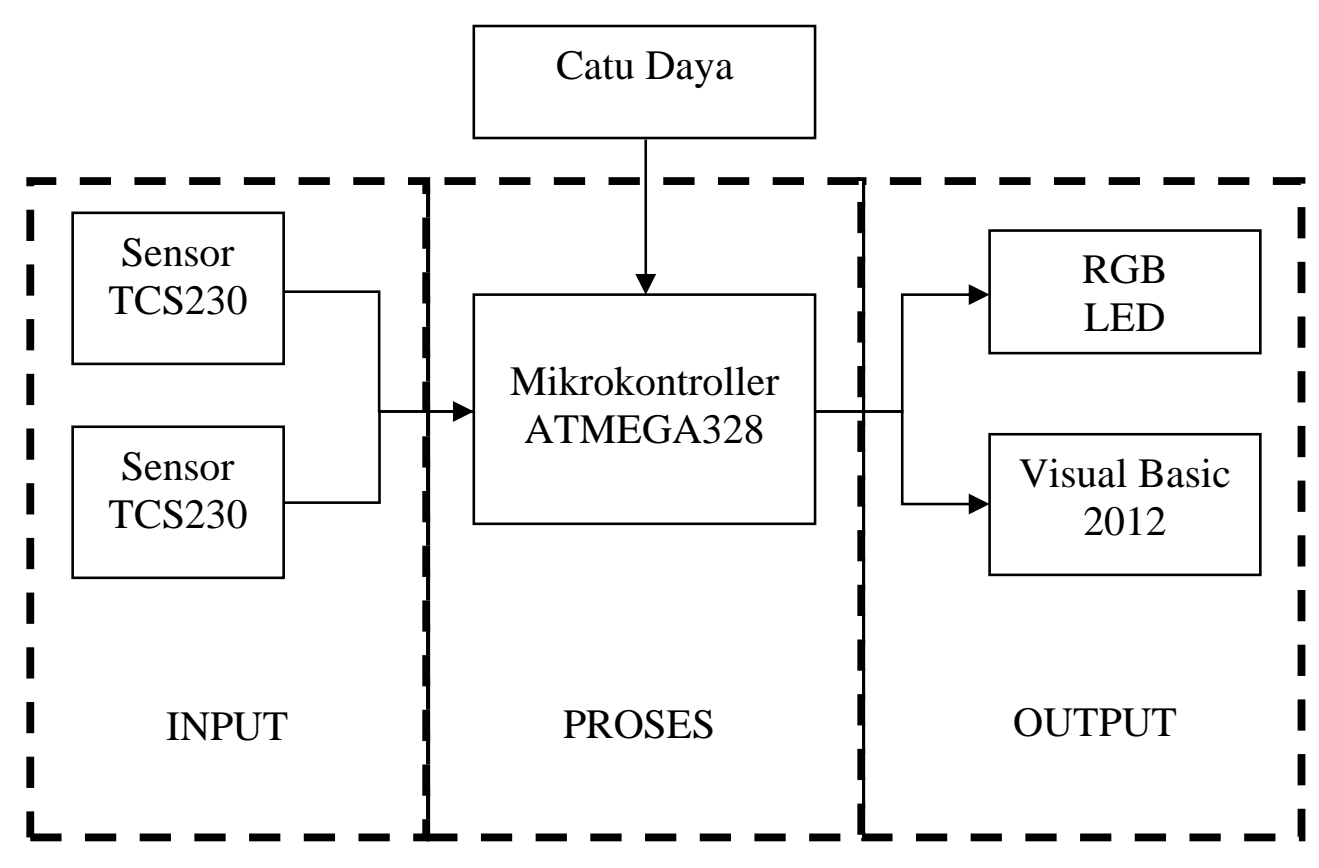

Gambar 2. Diagram Blok Rangkaian

Gambar 3 merupakan flowmap sistem. Dari gambar 3 dapat dijelaskan bahwa alat diaktifkan oleh user melalui aplikasi desktop berbasis Visual Basic 2012 dengan memilih port yang digunakan oleh alat dan menekan tombol "Connect". Selanjutnya user memasukkan kertas warna ke dalam alat, sehingga sensor TCS230 mendeteksi warna yang dipantulkan dari kartu 
warna kemudian hasil dari pendeteksian diproses oleh Mikrokontroller ATMEGA328 untuk memproses nilai warna yang masuk dan ditampilkan pada aplikasi desktop. Lampu RGB LED pada alat akan menyala dan berwarna sesuai dengan warna kertas yang dideteksi.

Aplikasi desktop akan melakukan inisialisasi jumlah warna yang dimasukkan, jika hanya terdeteksi satu warna maka hasil warna yang terdeteksi akan langsung ditampilkan pada layar desktop. Jika terdeteksi dua warna maka user dapat melihat kombinasi dari dua warna yang dimasukkan dengan menekan tombol "Kombinasi". Selanjutnya aplikasi akan memproses perintah kombinasi kemudian menampilkan warna hasil kombinasi pada layar desktop.

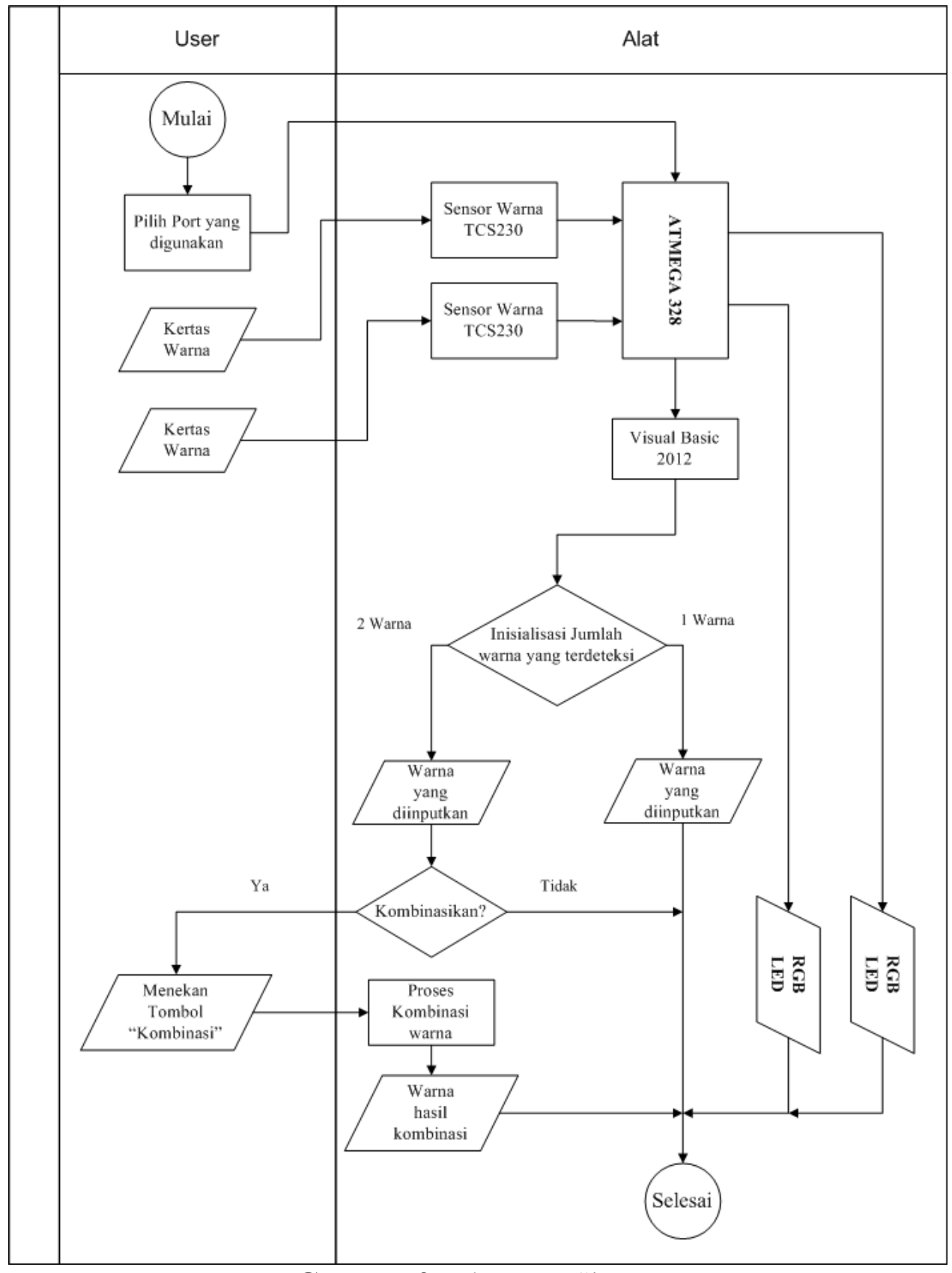

Gambar 3. Flowmap Sistem

Gambar 4 merupakan perancangan keseluruhan sistem alat. Rangkaian keseluruhan sistem alat terhubung ke Laptop yang sudah terpasang aplikasi pengenal warna berbasis Visual Basic 
2012 melalui kabel USB. Aplikasi ini berfungsi untuk menampilkan outputan data warna serta dapat diketahui hasil kombinasi warnanya.

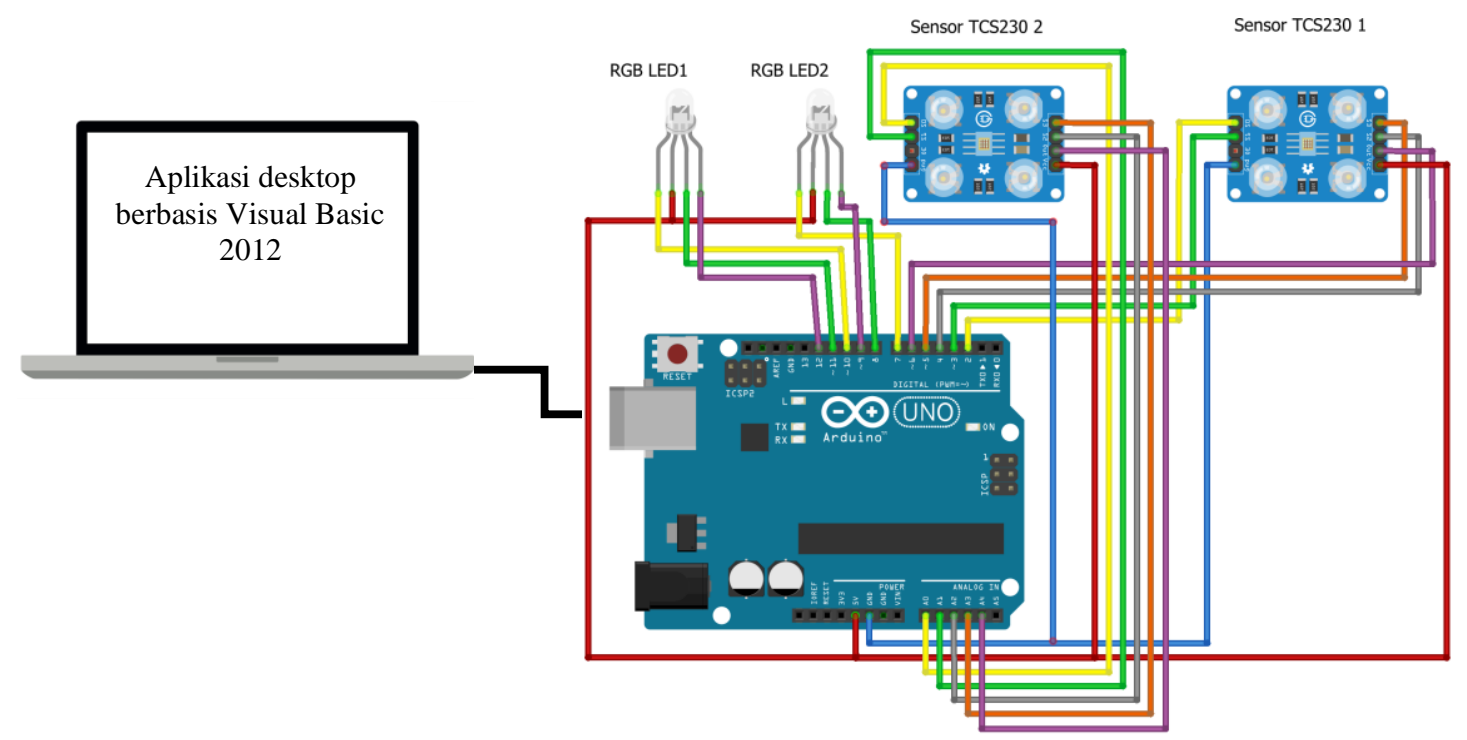

Gambar 4. Rangkaian keseluruhan sistem alat

Gambar 5 merupakan perancangan casing media pembelajaran kombinasi warna. Penulis memilih kayu triplex untuk pembuatan alat dengan pertimbangan murah, ringan dan mudah dibentuk. Untuk pembuatan kartu warna penulis memilih kayu triplek yang dilapisi sticker warna dengan tujuan agar tidak mudah rusak. Untuk tempat penyimpanan kartu disatukan dengan alat agar kartu tidak tercecer dan mudah hilang.

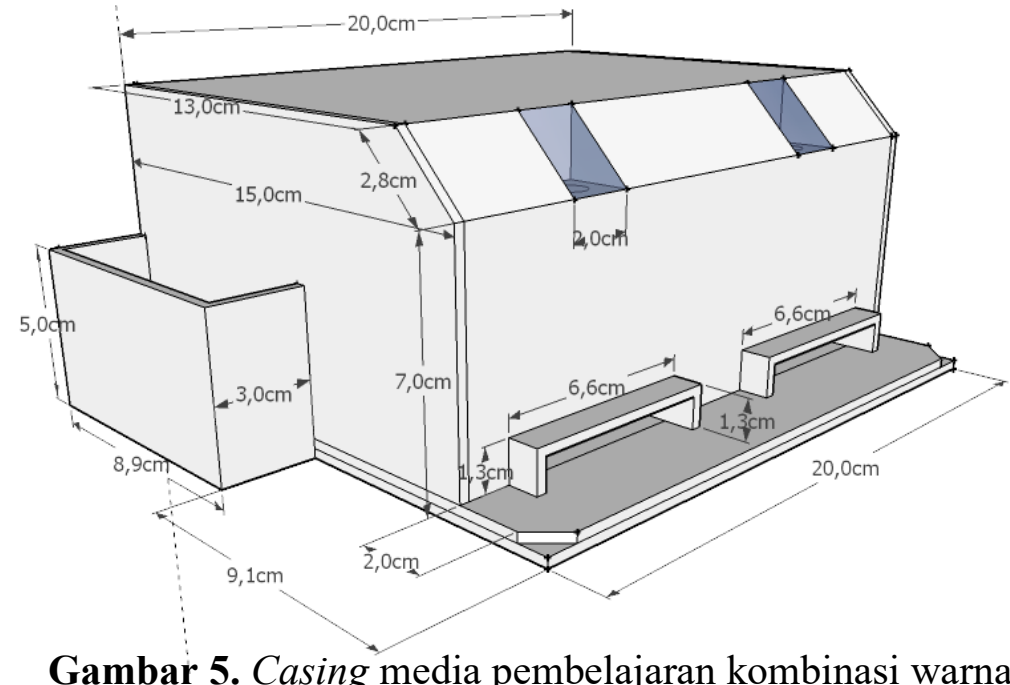

\subsection{Pembuatan}

Pembuatan alat dilakukan secara bertahap yaitu dengan membuat dan menempatkan komponen-komponen pada casing media pembelajaran. Gambar 6 merupakan penempatan masing-masing komponen pada casing alat. Pada gambar 6 terdapat beberapa komponen sebagai berikut: 1) Arduino Uno R3 berfungsi untuk pengolahan data input dan output dengan IC ATMEGA328 sebagai otak pengolah datanya; 2) Breadboard berfungsi untuk jumper penghubung antara kabel dari arduino dan komponen serta untuk memasang komponen 
tambahan seperti resistor; 3) Sensor TCS230 berfungsi untuk mendeteksi warna pada kartu warna yang dimasukkan.

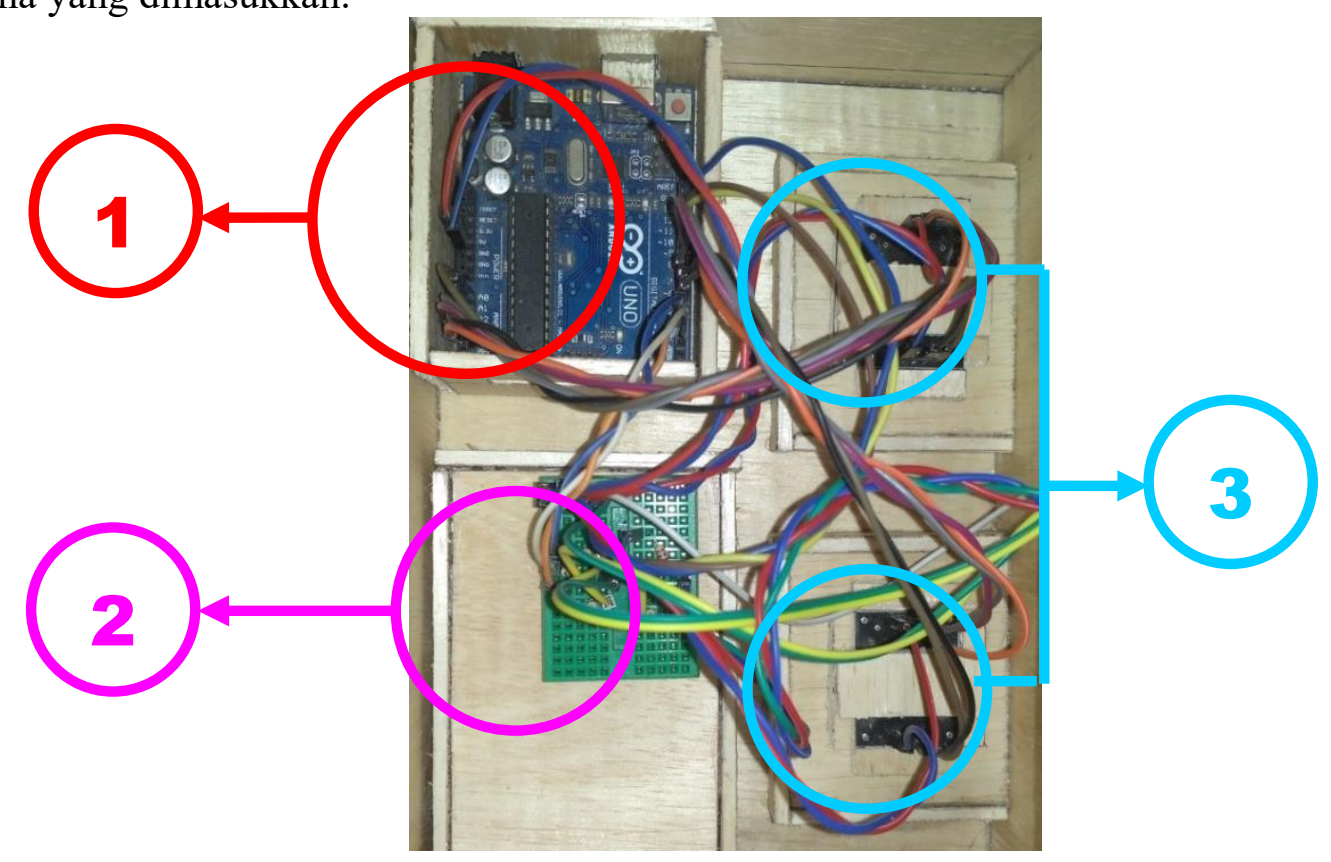

Gambar 6. Penempatan komponen pada casing alat.

Gambar 7 merupakan media pembelajaran kombinasi warna, dengan bagian sebagai berikut: 1) Slot kartu warna fungsinya untuk tempat memasukkan kartu warna; 2) Kartu warna fungsinya sebagai objek yang digunakan pada media pembelajaran ini sebagai pengganti cat warna; 3) RGB LED fungsinya untuk outputan berupa cahaya.

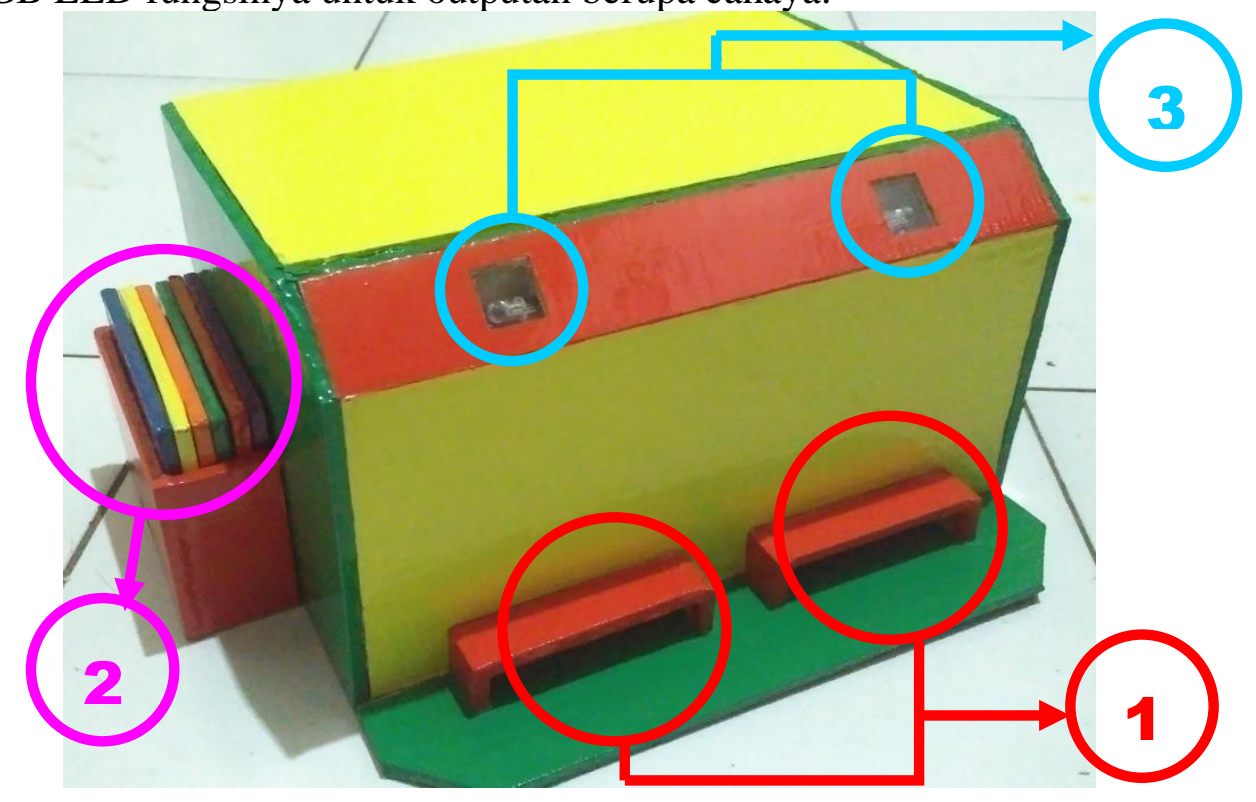

Gambar 7. Media pembelajaran kombinasi warna

Gambar 8 merupakan aplikasi media pembelajaran kombinasi warna yang dikembangkan berbasis Visual Basic 2012. Pada halaman depan aplikasi pengenalan warna, terdapat tombol yang terintegrasi dengan halaman inti. Selain itu, terdapat tombol "power" yang digunakan 
untuk mematikan aplikasi. Pada halaman utama pegguna dapat mengkombinasikan warna yang dimasukkan dalam alat dengan cara menekan tombol "Kombinasi". Pengguna juga dapat mendengarkan audio untuk mengetahui nama warna yang ditampilkan dengan menekan tombol yang bergambar "icon play".

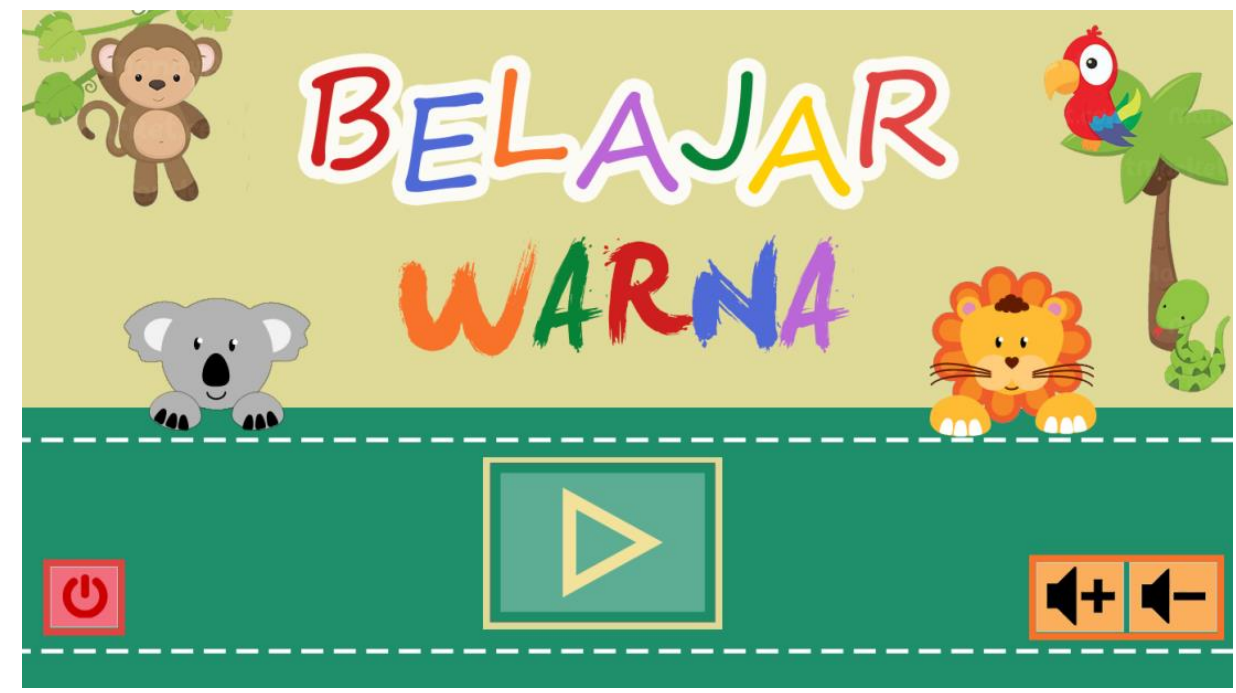

Gambar 8.a. Halaman depan aplikasi media pembelajaran kombinasi warna

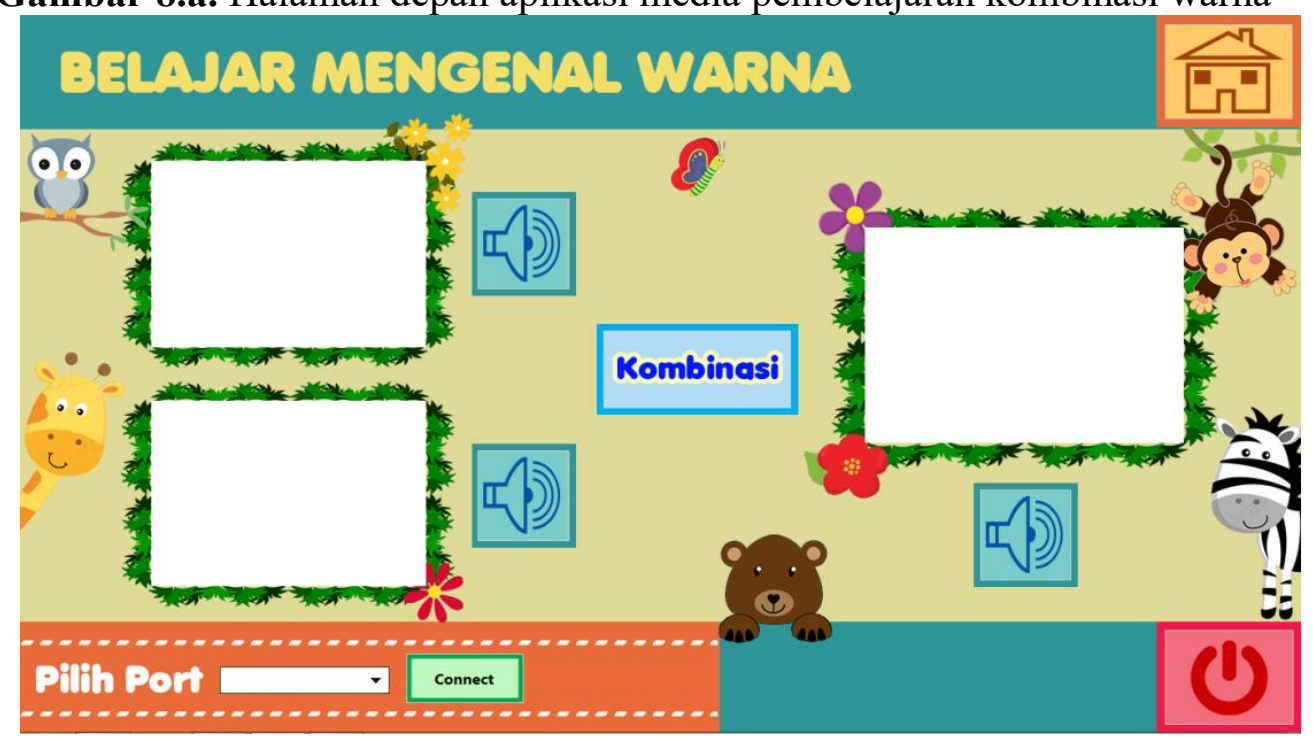

Gambar 8.b. Halaman utama aplikasi media pembelajaran kombinasi warna

\subsection{Pengujian}

Pengujian pada aplikasi dilakukan dengan beberapa metode, yaitu pengujian black box, pengujian sistem dan pengujian apikasi dengan membandingkan dengan teori warna Munsell (Cochrane, 2014) (Yogananti, 2015).

\subsubsection{Pengujian black box}

Pengujian black box berfokus pada persyaratan fungsional perangkat lunak meliputi tombol dan hasil output-an data, seperti di tampilkan pada tabel 1. Berdasarkan hasil pengujian pada tabel 1 menunjukkan bahwa semua tombol yang terdapat pada aplikasi media pembelajaran kombinasi warna dapat berfungsi dengan baik. 
Tabel 1. Hasil Pengujian black box

\begin{tabular}{llll}
\hline \multicolumn{1}{c}{ Data Masukan } & \multicolumn{1}{c}{ Yang Diharapkan } & \multicolumn{1}{c}{ Hasil Pengujian } & Keterangan \\
\hline $\begin{array}{l}\text { Klik tombol } \\
\text { "Simbol Play" }\end{array}$ & $\begin{array}{l}\text { Menampilkan halaman } \\
\text { kombinasi }\end{array}$ & $\begin{array}{l}\text { Halaman kombinasi } \\
\text { tampil. }\end{array}$ & Berhasil \\
\hline $\begin{array}{l}\text { Klik } \\
\text { tombol"Simbol } \\
\text { Shutdown" }\end{array}$ & $\begin{array}{l}\text { Menutup halaman utama } \\
\text { dan aplikasi. }\end{array}$ & $\begin{array}{l}\text { Halaman aplikasi } \\
\text { pengenalan warna akan } \\
\text { tertutup }\end{array}$ & Berhasil \\
\hline $\begin{array}{l}\text { Klik tombol } \\
\text { "Simbol Volume }\end{array}$ & $\begin{array}{l}\text { Volume suara pada } \\
\text { laptop/PC meningkat }\end{array}$ & $\begin{array}{l}\text { Volume pada laptop / PC } \\
\text { meningkat }\end{array}$ & Berhasil \\
\hline $\begin{array}{l}\text { Klik tombol } \\
\text { "Simbol Volume } \\
\text { Down" }\end{array}$ & $\begin{array}{l}\text { Volume suara pada } \\
\text { laptop/PC menurun }\end{array}$ & $\begin{array}{l}\text { Volume pada laptop / PC } \\
\text { menurun }\end{array}$ & Berhasil \\
\hline
\end{tabular}

\section{Kasus dan Hasil Uji Halaman Utama}

\begin{tabular}{llll}
\hline $\begin{array}{l}\text { Data warna dari } \\
\text { alat }\end{array}$ & $\begin{array}{l}\text { Panel berwarna sesuai } \\
\text { dengan warna kartu yang } \\
\text { dimasukkan }\end{array}$ & $\begin{array}{l}\text { Panel warna berwarna } \\
\text { sesuai dengan kartu warna } \\
\text { yang dimasukkan pada alat }\end{array}$ & Berhasil \\
\hline $\begin{array}{l}\text { Klik Tombol } \\
\text { Kombinasi }\end{array}$ & $\begin{array}{l}\text { Menampilkan data warna } \\
\text { hasil kombinasi dari dua } \\
\text { warna yang dimasukkan }\end{array}$ & $\begin{array}{l}\text { Warna hasil kombinasi } \\
\text { ditampilkan pada panel } \\
\text { hasil kombinasi }\end{array}$ & Berhasil \\
\hline $\begin{array}{l}\text { Klik tombol } \\
\text { "Simbol Play" }\end{array}$ & $\begin{array}{l}\text { Menghasilkan bunyi } \\
\text { nama warna yang } \\
\text { dimasukkan }\end{array}$ & $\begin{array}{l}\text { Speaker laptop akan } \\
\text { mengeluarkan suara nama }\end{array}$ & Berhasil \\
\hline $\begin{array}{l}\text { Klik tombol } \\
\text { keluar }\end{array}$ & $\begin{array}{l}\text { Menutup aplikasi } \\
\text { pengenalan warna }\end{array}$ & $\begin{array}{l}\text { Aplikasi pengenalan warna } \\
\text { tertutup }\end{array}$ & Berhasil \\
\hline
\end{tabular}

\subsubsection{Pengujian sistem}

Pada pengujian sistem, pengujian dilakukan untuk mengetahun bahwa hardware dan software pada aplikasi media pembelajaran kombinasi warna dapat berjalan dengan baik. Pada tabel 1 sudah disajikan pengujian terkait dengan software aplikasi pengenalan warna.Untuk pengujian sistem, sebelum melakukan pengujian perlu di lakukan sinkronisasi alat (hardware) dengan aplikasi yang bertujuan untuk mengengetahu bahwa alat dengan aplikasi sudah terhubung dan dapat saling mengirim data. Tabel 2 merupakan hasil pengujian sistem. Dari hasil pengujian Tabel 2 dapat diketahui bahwa antara alat dalam hal ini adalah RGB LED dan aplikasi menghasilkan luaran yang sama untuk masukkan yang sama, selain itu kombinasi warna dalam aplikasi juga berfungsi dengan baik. 
Tabel 2. Hasil pengujian sistem

\begin{tabular}{ccccccccc}
\hline \multirow{2}{*}{ No. } & \multicolumn{2}{c}{ Data Masukan } & \multicolumn{2}{c}{ Alat } & \multicolumn{3}{c}{ Aplikasi (Panel Warna) } & \multirow{2}{*}{ Keterangan } \\
& Warna & Warna & RGB & RGB & Panel 1 & Penel 2 & Hasil Kombinasi & \\
\hline 1 & Merah & Merah & Merah & Merah & Merah & Merah & Merah & Berhasil \\
\hline 2 & Kuning & Kuning & Kuning & Kuning & Kuning & Kuning & Kuning & Berhasil \\
\hline 3 & Hijau & Hijau & Hijau & Hijau & Hijau & Hijau & Hijau & Berhasil \\
\hline 4 & Biru & Biru & Biru & Biru & Biru & Biru & Biru & Berhasil \\
\hline 5 & Jingga & Jingga & Jingga & Jingga & Jingga & Jingga & Jingga & Berhasil \\
\hline 6 & Ungu & Ungu & Ungu & Ungu & Ungu & Ungu & Ungu & Berhasil \\
\hline 7 & Merah & Jingga & Merah & Jingga & Merah & Jingga & Jingga Kemerahan & Berhasil \\
\hline 8 & Kuning & Jingga & Kuning & Jingga & Kuning & Jingga & Jingga Kekuningan & Berhasil \\
\hline 9 & Merah & Ungu & Merah & Ungu & Merah & Ungu & Ungu Kemerahan & Berhasil \\
\hline 10 & Biru & Ungu & Biru & Ungu & Biru & Ungu & Ungu Kebiruan & Berhasil \\
\hline
\end{tabular}

\subsubsection{Pengujian teori warna Munsell}

Pengujian teori warna Munsell. dilakukan menggunakan cat warna air yang dicampurkan antara warna satu dengan yang lainnnya. Pengujian teori ini bertujuan untuk mengetahui kesesuaian kombinasi warnapada rumus tabel Teori Warna Munsell dengan kombinasi warna yang dihasilkan dengan pasta warna sebagai media pembelajaran yang digunakan pada saat ini di RA Al-Amin 3 Cemani. Tabel 3 merupakan hasil perbandingan rumus warna teori Munsell dengan dengan pengujian yang dilakukan mengunakan perncampuran pasta warna.

Tabel 3. Pengujian teori warna Munsell

\begin{tabular}{|c|c|c|c|c|c|c|c|}
\hline \multirow{2}{*}{ No. } & \multicolumn{3}{|c|}{ Rumus Teori Warna Munsell } & \multicolumn{3}{|c|}{ Pengujian dengan pasta warna } & \multirow{2}{*}{ Keterangan } \\
\hline & Warna 1 & Warna 2 & Hasil & Warna 1 & Warna 2 & Hasil & \\
\hline 1. & Merah & Jingga & $\begin{array}{c}\text { Jingga } \\
\text { Kemerahan }\end{array}$ & & & & Sesuai \\
\hline 2. & Kuning & Jingga & $\begin{array}{c}\text { Jingga } \\
\text { Kekuningan }\end{array}$ & & & & Sesuai \\
\hline 3. & Merah & Ungu & $\begin{array}{c}\text { Ungu } \\
\text { Kemerahan }\end{array}$ & & & & Sesuai \\
\hline 4. & Biru & Ungu & $\begin{array}{c}\text { Ungu } \\
\text { Kebiruan }\end{array}$ & & & & Sesuai \\
\hline 5. & Kuning & Hijau & $\begin{array}{c}\text { Hijau } \\
\text { Kekunigan }\end{array}$ & & & & Sesuai \\
\hline 6. & Biru & Hijau & $\begin{array}{c}\text { Hijau } \\
\text { Kebiruan }\end{array}$ & & & & Sesuai \\
\hline
\end{tabular}


Dapat dilihat pada table 3 bahwa perbandingan teori warna Munsell dengan pengujian menggunakan pasta warna memiliki hasil kombinasi warna yang sama (Resita, 2011). Berkaitan dengan data hasil pengujian di atas, menunjukkan bahwa hasil pengujian secara keseluruhan, media pembelajaran pengenalan warna dan kombinasi warna sudah dapat bekerja secara fungsional dalam mengkombinasikan warna sehingga media ini bisa dijadikan sebagai media pembelajaran kombinasi warna.

\section{KESIMPULAN}

Telah dikembangkan aplikasi media pembelajaran kombinasi warna dengan tahapan analisis, perancangan, pembuatan dan pengujian. Media pembelajaran pengenalan kombinasi warna dikembangkan dengan Arduino Uno R3 dan sensor warna TCS230 serta berbasis Visual Basic 2012. Jumlah warna yang dapat di kombinasikan oleh media pembelajaran ini hanya 2 warna karena hanya memiliki 2 slot yang digunakan untuk memasukkan kartu warna. Hasil pengujian media pembelajaran pengenalan warna dan kombinasi warna sudah dapat bekerja secara fungsional dalam mengkombinasikan warna sehingga media ini bisa dijadikan sebagai media pembelajaran kombinasi warna.

\section{DAFTAR PUSTAKA}

Cochrane, Sally (2014) The Munsell Color System: A scientific compromise from the world of art. Studies in History and Philosophy of Science 47, 26-41

Grindal, T., Bowne, J.B., Yoshikawa, H., Schindler, H.S., Duncan, G.J., Magnuson, K. \& Shonkoff, J.P. (2016). The added impact of parenting education in early childhood education programs: A meta-analysis, Children and Youth Services Review

Holis, Ade. (2016). Belajar Melalui Bermain untuk Pengembangan Kreativitas dan Kognitif Anak Usia Dini. Jurnal Pendidikan Universitas Garut. Vol. 09; No. 01

Muliani , N.M., Gading,I. K., Mahadewi, L.P.P. (2017). Pengaruh Metode Discovery Terhadap Kemampuan Mengenal Warna Pada Anak Taman Kanak-Kanak. Journal Pendidikan Anak Usia Dini Universitas Pendidikan Ganesha. Volume 5. No. 1

Nofitasari, A.D., Maryani, I. (2018). Efektifitas Metode Eksperimen Terhadap Kemampuan Mengenal Warna Di Kelas A TK ABA Tobayan Sleman. Jurnal Pendidikan:Early Childhood Vol. 2 No. 1

Resita, D.R.A, I. K. Jakti; Mita Purbasari (2011) Teori Yang Memperkuat Kebutuhan Penamaan Warna Untuk Buku Khazana Warna. HUMANIORA Vol.2 No.2 Oktober 2011: 1474-1482

Suciati, D.A.K.G., Suarni, N.K., Ujianti, P.R. (2016). Pengaruh Kegiatan Finger Painting Berbasis Teori Lokomosi Terhadap Keterampilan Motorik Halus Anak. Journal Pendidikan Anak Usia Dini Universitas Pendidikan Ganesha. Volume 4. No. 2

Yogananti, A. F (2015) Pengaruh Psikologi Kombinasi Warna Dalam Website. Andharupa: Jurnal Desain Komunikasi Visual \& Multimedia. Vol.01 No.01 